\title{
Influence of precipitation and dislocation substructure on phase transformation temperatures in a Ni-rich NiTi-shape memory alloy
}

\author{
J.K. Allafi, A. Dlouhy ${ }^{1}$, K. Neuking and G. Eggeler \\ Institut für Werkstoffe IA 1/125, Ruhr-Universität Bochum, 44780 Bochum, Germany \\ ${ }^{1}$ Institute of Physics of Materials, AS CR, Zizkova 22, 61662 Brno, Czech Republic
}

\begin{abstract}
The present work studies the influence of different thermo mechanical treatments on phase transformation and creep of a Ti-50.7at\%Ni shape memory alloy. Thermo-mechanically processed, solution annealed, tempered and pre-crept material states show different phase transformation behaviour. Precipitation of $\mathrm{Ti}_{3} \mathrm{Ni}_{4}$ particles can rationalize a $20^{\circ} \mathrm{C}$ increase in phase transition temperatures. Changes of dislocation density and subgrain size also have a systematic but small effect on the martensitic transformation. There is a strong influence of small preloads on the shape of individual creep curves in the early stages of creep which is associated with the precipitation of $\mathrm{Ti}_{3} \mathrm{Ni}_{4}$.
\end{abstract}

\section{INTRODUCTION}

Nickel rich near-equiatomic Ti-Ni shape memory alloys (SMAs), while fully annealed, martensitically transform on cooling from a cubic phase B2 into a low temperature phase B19' [1-3]. After thermomechanical treatments the near-equiatomic $\mathrm{Ti}-\mathrm{Ni}$ alloys can transform in two steps, i.e., from the B2 parent to the R-phase and then to the B19' phase. During heating, either the reverse sequence B19' $\rightarrow$ R $\rightarrow$ B2 [e.g. 4,5] or a direct transformation B19' $\rightarrow$ B2 is obtained, depending on the thermal treatment [e.g. 6]. Throughout the present work we refer to the B2-phase as austenite (A) and to the B 19'-phase as martensite (M); $\mathrm{R}$ is used as an abbreviation for the $\mathrm{R}$-phase. We also refer to the first DSC-peak which occurs on cooling in a two phase transformation as R-phase. Creep properties of NiTi SMAs have so far received only limited attention in the literature [7-9]. This is somewhat unfortunate mainly because micro creep processes govern the relaxation of stresses during shaping of spring wires for the one way shape memory effect. Moreover, during hot deformation in the B2 regime, lattice defects are introduced into the austenite and these have been shown to interact with the martensitic phases which form during cooling [10,11]. The present study provides creep data for a NiTi rich SMA and discusses the shape of individual creep curves on a microstructural basis. It also investigates the role of temperature, stress and strain on the precipitation of $\mathrm{Ti}_{3} \mathrm{Ni}_{4}$ and on phase transition temperatures (PTTs).

\section{EXPERIMENTS}

Two rods ( $\mathrm{A}$ and $\mathrm{B}$ ) from one batch of a binary $\mathrm{Ti}-50.7 \mathrm{at} \% \mathrm{Ni}$ alloy were investigated in the present study (length: $800 \mathrm{~mm}$, diameter: $13 \mathrm{~mm}$ ). Phase transformation temperatures (PTTs) were measured for the as received, tempered and crept material using a differential scanning calorimeter DSC $912 \mathrm{~S}$ from TA Instruments. All PTTs determined in the present study are summarized in Table 1. For the as received and solution annealed materials DSC measurements were performed for both sides of the rods (left -1 and right $-r$ ). The PTTs are characterized by the start, peak and finish temperatures. Cylindrical specimens (25 mm gauge length, $5 \mathrm{~mm}$ gauge diameter, $8 \mathrm{~mm}$ diameter in the specimen thread) were crept in air under constant load in the temperature range $773-833 \mathrm{~K}\left(500-560^{\circ} \mathrm{C}\right)$. The applied loads corresponded to stresses between 120 and $180 \mathrm{MPa}$. It was found that the shapes of the early parts of the creep curve show a strong dependence on the preload applied prior to creep testing, Figure 1. Preloads of $10 \mathrm{MPa}$ result in sharp creep rate minima at very small strains of the order of $0.1 \%$. At a preload corresponding to 
Table 1: Phase transition temperatures (PTTs) [ $\left.{ }^{\circ} \mathrm{C}\right]$ as determined by DSC-measurements for specific material states, Abbreviations: A, B - specimens from bar A or B respectively; $1, \mathrm{r}-\mathrm{DSC}$-specimens from left respectively right end of bar, ar - as received material, sa - solution annealed material, ag - aged material, A 5a and A 5b - two DSC specimens from one creep specimen ( $a$ - undeformed specimen thread, b - crept material state). $A_{S^{-}}, A_{p}$ and $A_{f-}$ austenite start, peak and finish temperatures, similar subscripts hold for $\mathbf{R}$ - and $\mathbf{M}$ - transformation temperatures. *: Strong overlap of $\mathrm{R}$ - and $\mathbf{M}$-peaks.

\begin{tabular}{|c|c|c|c|c|c|c|c|c|c|c|c|}
\hline no. & state & pos. & $\mathbf{A}_{\mathbf{s}}$ & $\mathbf{A}_{\mathbf{p}}$ & $\mathbf{A}_{\mathbf{f}}$ & $\mathbf{R}_{\mathbf{s}}$ & $\mathbf{R}_{\mathbf{p}}$ & $\mathbf{R}_{\mathbf{f}}$ & $\mathbf{M}_{\mathbf{s}}$ & $\mathbf{M}_{\mathbf{p}}$ & $\mathbf{M}_{\mathbf{f}}$ \\
\hline A 1 & as received (ar) & 1 & 16 & 26 & 30 & - & - & - & 1 & -5 & -11 \\
\hline A 2 & $"$ & $\mathrm{r}$ & 16 & 29 & 33 & - & - & - & 2 & -7 & -16 \\
\hline A 3 & $\mathrm{ar}+850^{\circ} \mathrm{C}, 15 \mathrm{~min}(\mathrm{sa})$ & 1 & 16 & 26 & 30 & - & - & - & 1 & -5 & -12 \\
\hline A 4 & " & $\mathrm{r}$ & 16 & 29 & 33 & - & - & - & 2 & -7 & -16 \\
\hline A 5a & ar $+500^{\circ} \mathrm{C}, 23 \mathrm{hrs}$, thread & - & 44 & 50 & 54 & 29 & 25 & 22 & 11 & 5 & -1 \\
\hline A 5b & $\mathrm{ar}+500^{\circ} \mathrm{C}, 23 \mathrm{hrs}$, crept: $120 \mathrm{MPa}, 2 \%$ & - & 40 & 46 & 51 & 28 & 24 & 19 & 14 & 5 & -2 \\
\hline A 6a & ar $+500^{\circ} \mathrm{C}, 185 \mathrm{hrs}$, thread & - & 44 & 52 & 56 & 30 & 26 & 24 & 19 & 10 & 2 \\
\hline $\mathbf{A} \mathbf{6 b}$ & ar $+500^{\circ} \mathrm{C}, 185 \mathrm{hrs}$, crept: $120 \mathrm{MPa}, 18 \%$ & - & 41 & 51 & 58 & 29 & 23 & $*$ & $*$ & $*$ & 7 \\
\hline B 1 & as received (ar) & 1 & 14 & 24 & 29 & - & - & - & -2 & -8 & -18 \\
\hline B 2 & " & $r$ & 15 & 26 & 31 & - & - & - & 1 & -8 & -17 \\
\hline B 3 & ar $+850^{\circ} \mathrm{C}, 15 \min (\mathrm{sa})$ & 1 & 16 & 31 & 37 & - & - & - & 5 & -6 & -16 \\
\hline B 4 & " & $r$ & 18 & 31 & 37 & - & - & - & 6 & -4 & -15 \\
\hline B 5 & $\mathrm{ar}+\mathrm{sa}+550^{\circ} \mathrm{C}, 1 \mathrm{~h}(\mathrm{ag})$ & 1 & 21 & 34 & 40 & - & - & - & 4 & -6 & -14 \\
\hline B 6 & " & $\mathrm{r}$ & 20 & 31 & 37 & - & - & - & 5 & -3 & -13 \\
\hline B 7a & ar $+500^{\circ} \mathrm{C}, 66 \mathrm{hrs}$, thread & - & 43 & 52 & 58 & 25 & 19 & 10 & 20 & 7 & -2 \\
\hline B 7b & ar $+500^{\circ} \mathrm{C}, 66 \mathrm{hrs}$, crept: $150 \mathrm{MPa}, 30 \%$ & - & 38 & 51 & 63 & 23 & 16 & 4 & 18 & 4 & -6 \\
\hline B 8a & ar $+\mathrm{sa}+500^{\circ} \mathrm{C}, 50 \mathrm{hrs}$, thread & - & 43 & 54 & 61 & 27 & 20 & * & $*$ & 8 & -2 \\
\hline B 8b & $\mathrm{ar}+\mathrm{sa}+500^{\circ} \mathrm{C}, 50 \mathrm{hrs}, \mathrm{crept}: 150 \mathrm{MPa}, 10 \%$ & - & 40 & 51 & 58 & 25 & 16 & $*$ & * & 7 & -2 \\
\hline B 9a & $\mathrm{ar}+\mathrm{sa}+\mathrm{ag}+500^{\circ} \mathrm{C}, 57 \mathrm{hrs}$, thread & - & 45 & 53 & 57 & 28 & 23 & 18 & 18 & 8 & 2 \\
\hline B 9b & $\mathrm{ar}+\mathrm{sa}+\mathrm{ag}+500^{\circ} \mathrm{C}, 57 \mathrm{hrs}$, crept: $150 \mathrm{MPa}, 10 \%$ & - & 38 & 47 & 53 & 25 & 18 & $*$ & $*$ & 7 & -1 \\
\hline
\end{tabular}

$2 \mathrm{MPa}$ no such sharp minimum is observed; preloads within the present study were limited to $2 \mathrm{MPa}$. Transmission electron microscopy (TEM) was performed using a Philips CM20 analytical microscope operating at $200 \mathrm{kV}$. TEM foils were thinned by a standard double jet technique (TENUPOL) with the Struers $\mathrm{A} 8$ electrolyte at $65 \mathrm{~V}$ and $15^{\circ} \mathrm{C}$.

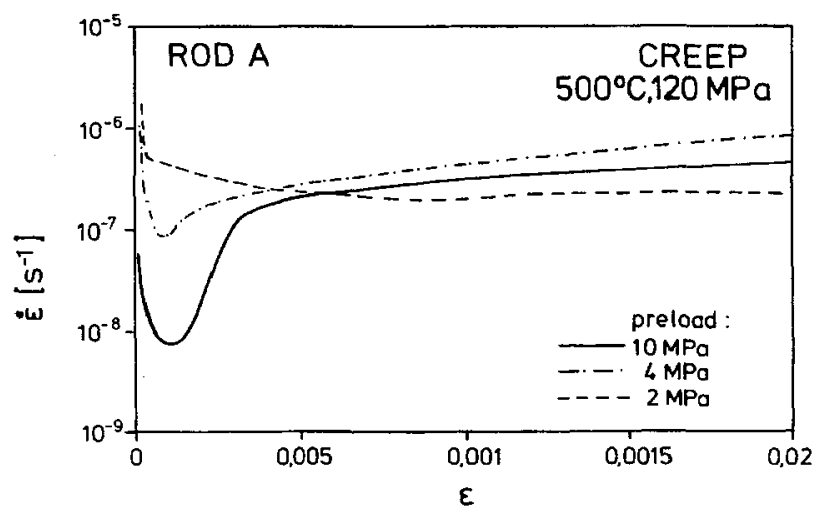

Figure 1: Creep curves showing an effect of pre-load on the shape of individual creep curves (material of bar A, T: $500^{\circ} \mathrm{C}, \sigma: 120$ $\mathrm{MPa})$. 


\section{RESULTS}

The PTTs of the as received material change when the alloy is subjected to different thermal or thermo mechanical treatments. The DSC chart of the as received material exhibit no R-phase peak. Neither were R-phase peaks observed in materials after solution annealing at $850^{\circ} \mathrm{C}$ for 15 minutes (sa) with and without an additional aging treatment at $550^{\circ} \mathrm{C}$ for 1 hour (ag). Additional R-phase peaks were observed after creep testing, both in the thread and in the gauge length. Material states after creep also exhibit a shift of all PTTs towards higher temperatures, Table 1. Thus the peak associated with the formation of austenite on heating is shifted upwards by $20^{\circ} \mathrm{C}$. The same holds for the temperatures which characterize the formation of martensite (M-PTTs for the as received material and (M+R)/2-PTTs for the stress exposed tempered material). As compared to the as-received material of rod $\mathrm{B}$ a small but systematic increase of 4 to $6^{\circ} \mathrm{C}$ of M- and A-PTTs was found after solution annealing. Similarly, as compared to the gauge length sections of crept specimens, the undeformed specimen threads show a small but systematic increase of all PTTs by 2 to $4^{\circ} \mathrm{C}$. Three creep curves obtained at $500^{\circ} \mathrm{C}$ and $150 \mathrm{MPa}$ for rod B material subjected to different heat treatments are plotted in Figure 2. The creep curve of the as-received material shows a shallow creep rate minimum. The two heat-treated material states show a sharp creep rate minimum within the first percent of strain. The lowest creep rate was obtained for the solution annealed and tempered material state. For all three material states there is an increase of creep rate after the creep rate minimum and eventually all three curves level out and reach creep rates of the order of $10^{-6} \mathrm{~s}^{-1}$. Figure $3 \mathrm{a}$ shows the dislocation substructure within the as received material of rod $\mathrm{B}$. Besides the $\mathrm{Ti}_{4} \mathrm{Ni}_{2} \mathrm{O}$ oxides (up to $1 \mu \mathrm{m}$ in size) no other precipitates could be detected in the as received material of rod $\mathrm{B}$. The same precipitation structure was detected after solution annealing (oxides denoted by an arrow in Figure $3 b$ ). Solution annealing decreases the dislocation density associated with the thermo mechanical treatment of the as received material by recovery and recrystallization processes. Nickel rich precipitates of type $\mathrm{Ti}_{3} \mathrm{Ni}_{4}$ were found in the thread of a creep specimen, Figure 3c. Significantly larger $\mathrm{Ti}_{3} \mathrm{Ni}_{4}$ particles were observed in the thread of a creep specimen after longer exposure at higher applied stress, Figure $3 \mathrm{~d}$. The volume fraction of $\mathrm{Ni}$-rich $\mathrm{Ti}_{3} \mathrm{Ni}_{4}$-precipitates in the material state corresponding to Figure $3 \mathrm{~d}$ was determined as $4.1 \%$. The TEM-micrograph from which the particle volume fraction was obtained is shown in Figure 4a. Figure $4 \mathrm{~b}$ shows one martensite needle (indicated by an arrow) in the solution annealed material of bar $\mathrm{B}$. The martensite needle has propagated up to a subgrain boundary which presents an obstacle to the motion of the martensite/austenite-interface.

\section{DISCUSSION}

Precipitation of $\mathrm{Ti}_{3} \mathrm{Ni}_{4}$ particles was documented in Figures 3d and 4a. For the microstructure presented in these figures an increase of $20^{\circ} \mathrm{C}$ in PTTs is observed, Table1. In order to interpret this effect we use a

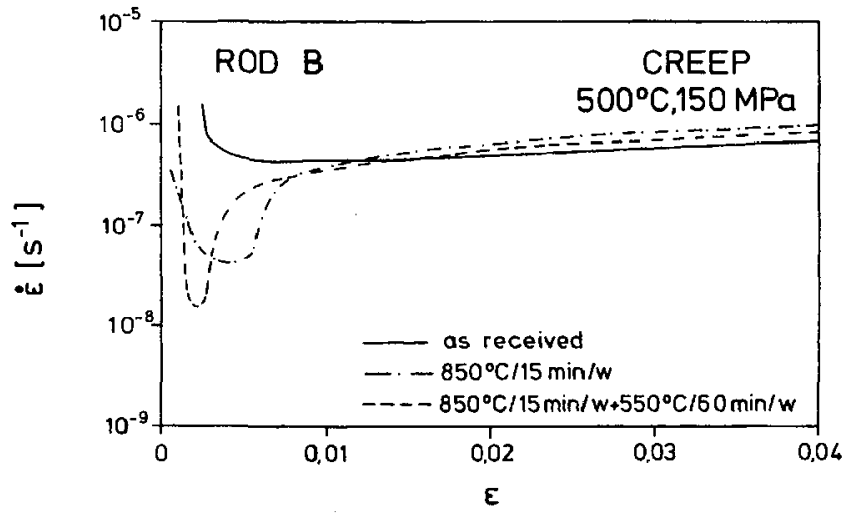

Figure 2: Creep curves (log-creep rate vs. creep strain) of bar B material with different heat treatments ( $\left.\mathrm{T}: 500^{\circ} \mathrm{C}, \sigma: 150 \mathrm{MPa}\right)$. 

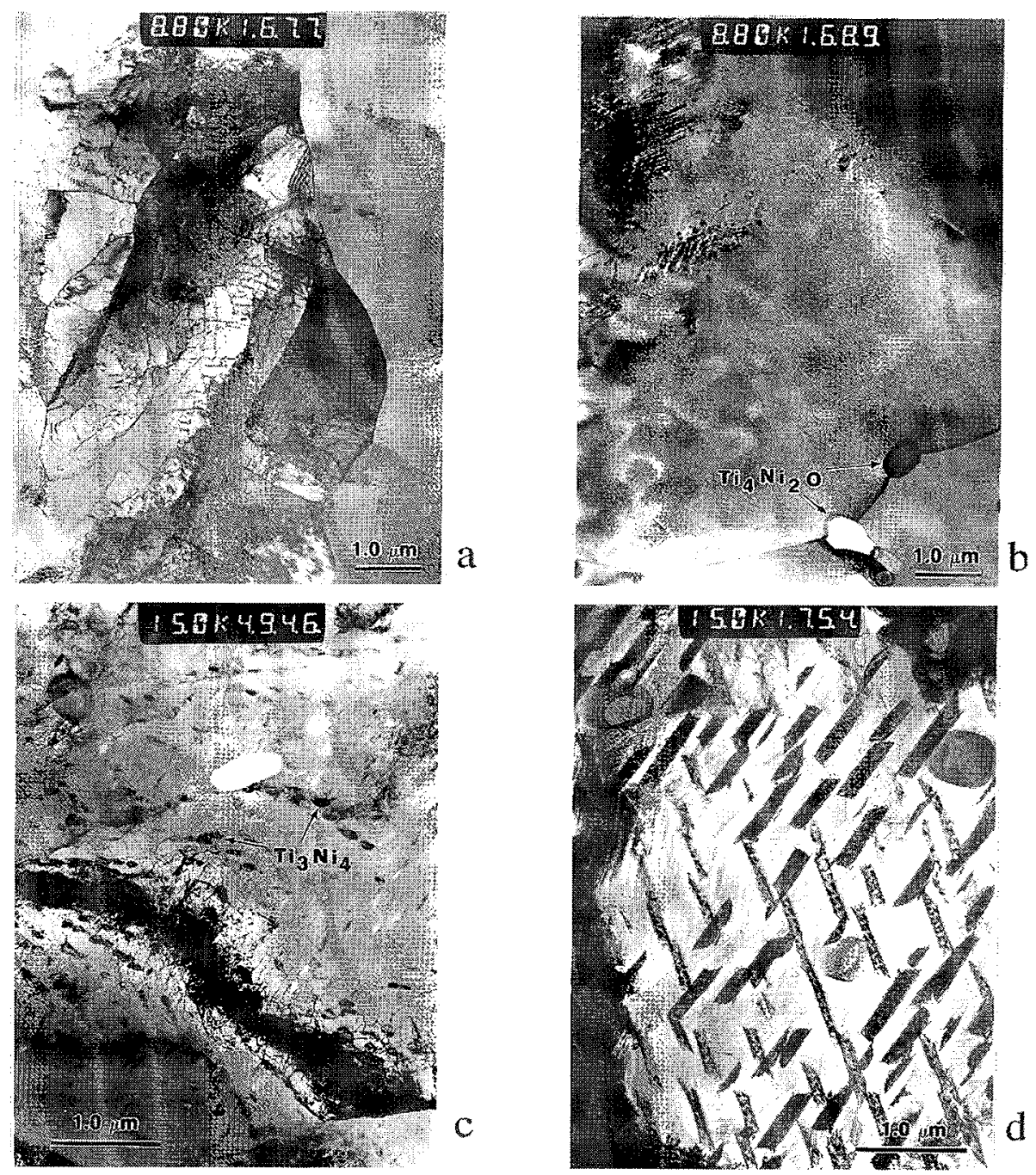

Figure 3: TEM micrographs of four different B2-phase microstructures observed in the Ti-50.7at\% $\mathrm{Ni}$ alloy: (a) as received material (rod B), (b) solution annealed material state (rod B: $850^{\circ} \mathrm{C} / 15$ minutes), (c) undeformed thread of a creep specimen (mild creep exposure - rod $\mathrm{A}, 500^{\circ} \mathrm{C}$, creep loading: $120 \mathrm{MPa}$, average stress estimated for the creep specimen thread: $47 \mathrm{MPa}, 23$ hours), (d) undeformed thread of a creep specimen (severe creep exposure - rod $\mathrm{B}, 500^{\circ} \mathrm{C}$, creep loading: $150 \mathrm{MPa}$, average stress estimated for the creep specimen thread: $59 \mathrm{MPa}, 50$ hours).

linearization of published data on the dependence of $\mathrm{M}_{\mathrm{S}}$ on the nickel content in the matrix $\mathrm{c}_{\mathrm{Ni}}[3,12]$ :

$$
\mathrm{S}=\frac{\Delta \mathrm{M}_{\mathrm{s}}}{\Delta \mathrm{c}_{\mathrm{Ni}}}=-85\left({ }^{\circ} \mathrm{C} / \text { at. } \%\right)
$$

(S - slope, $\Delta \mathrm{M}_{\mathrm{s}}$ - change in martensite start temperature, $\Delta \mathrm{c}_{\mathrm{Ni}}$ - change of nickel concentration in the matrix, at.\% - concentration of nickel in atom percent.) Using Equation 1 and assuming that $\Delta\left(\left(\mathrm{M}_{\mathrm{s}}+\mathrm{R}_{\mathrm{s}}\right) / 2\right)$ of $20^{\circ} \mathrm{C}$ can be used instead of $\Delta \mathrm{M}_{\mathrm{s}}$, a decrease of 0.23 at.-\% Ni is obtained for $\Delta c_{\mathrm{Ni}}$. 

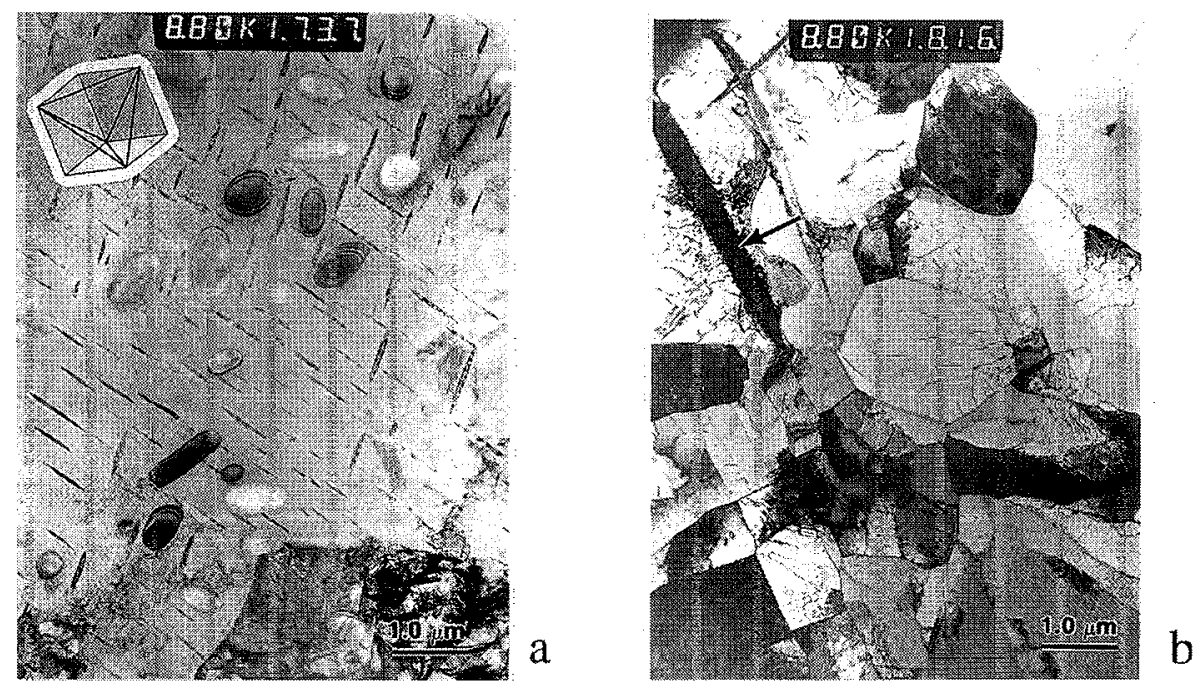

Figure 4: TEM-micrographs showing (a) an area from which the particle volume fraction was determined (material state corresponds to the microstructure of specimens B 8 a in Table 1) and (b) a solution annealed material state from bar B with a propagating martensite needle (probably introduced by TEM specimen preparation - stress induced martensite).

This decrement can only be accounted for in terms of precipitation, if it can be rationalized in terms of the overall $\mathrm{Ni}$-balance in the alloy

$$
\Delta c_{N i}=c_{N i}-c_{N i}^{0}=\frac{f_{p}\left(c_{N i}{ }^{0}-c_{p}\right)}{1-f_{p}}
$$

where $\mathrm{c}_{\mathrm{Ni}}{ }^{\circ}$ is the concentration of nickel in the alloy (matrix and particles), $c_{\mathrm{p}}$ the concentration of $\mathrm{Ni}$ in the particles ( 56 or 57.14 at.-\% depending on whether the particle is of type $\mathrm{Ti}_{11} \mathrm{Ni}_{14}$ or $\mathrm{Ti}_{3} \mathrm{Ni}_{4}$ ) and $f_{p}$ is the volume fraction of particles ( $4.1 \%$, see previous section). Evaluation of Equation 2 yields decreases of 0.22 and 0.27 at. $\%$ depending on the type of particles $\left(\mathrm{Ti}_{11} \mathrm{Ni}_{14}\right.$ or $\left.\mathrm{Ti}_{3} \mathrm{Ni}_{4}\right)$. A direct comparison of these results suggests that shifts in PTTs are associated with the precipitation of $\mathrm{Ti}_{3} \mathrm{Ni}_{4}$. Our results show that the method described in [13] can be experimentally validated. There is an interaction between martensitic phases and subgrain boundaries as has already been observed [9] and described [9, 11] in the literature and which was again identified in the present study, Figure 4b. This interaction has been interpreted as a stabilizing effect of the dislocation substructure on the austenite on cooling $[9,11]$ by hindering martensite needles to cross subgrain boundaries. This explains why the DSC-peaks of the Rand M-phase are shifted towards lower temperatures when the material contains a dislocation substructure. However, the results of the present study show, that this effect does not account for more than $6^{\circ} \mathrm{C}$ for subgrain sizes of the order of $1 \mu \mathrm{m}$. The TEM results presented in Figure $3 \mathrm{c}$ and $3 \mathrm{~d}$ show that the nucleation and growth of $\mathrm{Ni}$-rich particles is sensitive to stress and exposure time. Therefore, we suggest that the sharp decrease of creep rate under a preload of $10 \mathrm{MPa}$ (Figure 1) is associated with continuous precipitation processes (during preloading and creep) which influence both dislocation velocity and mobile dislocation density. This effect only ceases for preloads as small as $2 \mathrm{MPa}$. Further work is required to quantitatively account for preload effects on creep. It is less surprising that different heat treatments result in different creep behaviour, Figure 2. It is interesting to note that the more the as received material is subjected to the specific annealing and tempering conditions, the lower creep rates and the sharper creep rate minima are observed. Further investigation is required to understand these influences. 


\section{SUMMARY AND CONCLUSIONS}

The present work studies the influence of different thermo mechanical treatments on the phase transformation and creep behaviour of a Ni-rich NiTi-shape memory alloy. From the results obtained in the present study the following conclusions can be drawn:

Different microstructures (thermomechanically processed, solution annealed, tempered and pre-crept) show different phase transformation temperatures. This is related to precipitation processes during tempering and during creep and can be attributed to two effects: $\mathrm{Ni}$-rich precipitates change the $\mathrm{Ni}$ content of the surrounding matrix; they moreover give rise to elastic distortions on their appearance in the B2-phase.

Additional creep strain accumulation has a systematic but small effect on the formation of martensitic phases through the interaction of subgrain boundaries with moving austenite / martensite-interfaces.

In the early stages of creep, the shapes of individual creep curves obtained at a temperature of $500^{\circ} \mathrm{C}$ and stresses of $120 \mathrm{MPa}$ and $150 \mathrm{MPa}$ were found to be strongly dependent on the thermo mechanical treatment of the specimens prior to creep testing. These effects are most probably associated with the nucleation and growth of $\mathrm{Ni}$-rich precipitates.

\section{Acknowledgements}

JKA, KN and GE would like to thank the Deutsche Forschungsgemeinschaft for funding this study in the framework of the SFB 459 (Shape Memory Technology). AD acknowledges funding through the Grant Agency of the Czech Republic under contract no: 106/99/1172.

\section{References}

1. C.M. Wayman, T.W. Duerig, in Engineering Aspects of Shape Memory Alloys, edited by T.W. Duerig et al. (Butterworth-Heinemann Ltd., Essex 1990), p. 3.

2. E. Hornbogen, in Advanced Structural and Functional Materials, edited by W.G.J. Bunk (Springer Verlag, Berlin 1991), p. 133.

3. K. Otsuka, C.M. Wayman, Shape Memory Materials, edited by K. Otsuka, C.M. Wayman (Cambridge University Press, Cambridge 1998).

4. T. Todoroki, H. Tamura, Y. Suzuki, in ICOMAT-86, (The Japan Institute of Metals, Sendai, 1986), p. 748.

5. T. Tadaki, J. Nakata, K. Shimizu, Trans. Jpn. Inst. Met. 28, 883 (1987).

6. A.P. Jardine, K.H.G. Ashbee, M.J. Bassett, J. Mater. Sci. 23, 4273(1988).

7. A.K. Mukherjee, J. Appl. Phys. 39, 2201 (1968).

8. S.E. Hsu, M.T. Yeh, I.C. Hsu, S.C. Yang, C.Y. Wang, in Creep and Fract. of Eng. Materials and Structures, edited by J.C. Earthman, F.A. Mohamed (TMS, 1997), p. 567.

9. G.F. Eggeler, K. Neuking, A. Dlouhy, E. Kobus, Materials Science Forum 327-328, 183 (2000).

10. E. Hornbogen, J. Mater. Sci. 33, 1 (1998).

11. H. Morawiec, J. Ilczuk, D. Stroz, T. Goryczka, D. Chrobak, J. Phys. IV France 7, C5-155 (1997).

12. T.W. Duerig, A.R. Pelton, Materials Properties Handbook, (ASM International, Ti-Alloys, 1994), p. 1035.

13. K. Gall, H. Sehitoglu, Y.I. Chumlyakov, I.V. Kireeva, H.J. Maier, J. Eng. Matls. Techn. 121, 19 (1999). 